\title{
Structure and thermal stability in hydrophobic Pluronic F127-modified silica aerogels
}

\author{
Taína Z. Fermino, Carlos M. Awano, Leandro X. Moreno, Dimas R. Vollet, Fabio S. de Vicente* \\ Universidade Estadual Paulista (Unesp), Instituto de Geociências e Ciências Exatas, Departamento de Física, 13506-900, Rio Claro, SP, Brazil
}

\section{A R T I C L E I N F O}

\section{Keywords:}

Hydrophobic aerogels

Thermal treatment

SAXS

Nitrogen adsorption

Thermogravimetric analysis

\begin{abstract}
A B S T R A C T
Hydrophobic ambient pressure drying (APD) aerogels were prepared from hydrolysis of tetraethylorthosilicate (TEOS) in solutions with different concentrations of poly(ethylene oxide)-poly(propylene oxide)-poly(ethylene oxide) (F127). APD was carried out after silylation of wet gels with $20 \%$ by volume of hexamethyldisilazane (HMDZ) in n-hexane. The samples were analyzed by small-angle X-ray scattering (SAXS) and nitrogen adsorption. The APD aerogels obtained in this process were submitted to heat treatment at $300,500,700$ and $900{ }^{\circ} \mathrm{C}$ to study the pores stability. The samples were characterized by nitrogen adsorption. Wet gels are formed by massfractal domains, with fractal dimension close to 2.1 and characteristic size $(\xi)$ spanning from about $9 \mathrm{~nm}$ (for the gel prepared without the addition of F127) up to values that exceed the maximum limit of the SAXS experimental setup, with increasing the concentration of F127. Nitrogen adsorption data showed that the pore volume $\left(V_{\mathrm{p}}\right)$ and the mean pore size $\left(l_{\mathrm{p}}\right)$ of the aerogels increased with increasing the concentration of F127. The drying process diminished the characteristic size $\xi$ and increased the dimension $D$ of the mass-fractal domains and the size $\left(r_{0}\right)$ of the primary particles of the aerogels with respect to the wet gels. The characteristic size $\xi$ of the massfractal of the aerogels was found significantly larger with increasing the concentrations of F127. Thermally treated aerogels exhibited a similar general behavior with temperature independent of the concentration of F127. The porosity was found fairly stable up to about $500^{\circ} \mathrm{C}$. The porosity started to be eliminated at $700{ }^{\circ} \mathrm{C}$ and it was found practically collapsed at $900^{\circ} \mathrm{C}$. The silylation layer on the silica surface of the present APD aerogels was promptly eliminated at about $350^{\circ} \mathrm{C}$ yielding complete loss of hydrophobicity.
\end{abstract}

\section{Introduction}

Since the discovery of the amphiphilic properties and of the micelles formation in aqueous solution of the system copolymer tri-block poly (ethylene oxide) - poly(propylene oxide) - poly(ethylene oxide) [1,2], many scientific and technological advances have been achieved, using this and others similar surfactants in the preparation of the mesoporous silica, often resulting in interesting ordered pore structures [3,4]. In the preparation of composites, the copolymers block are an interesting class of structure modifier agents because the micelle structuration can determine the formation of the organized molds during the synthesis of the composites. These copolymers have advantage as their ordering way can be tailored by factors as solvent composition, molecular weight or copolymer architecture [3,4]. The use of the copolymer tri-block as impregnate structure agent in the silica polymerization process has allowed the preparation of ordered mesoporous silica with cubic arrangement and others forms [4-6].

Mesoporous silica shows interesting structural characteristics, including high specific surface area and pore volume, making this material of great scientific and technological interest for applications in many knowledge areas. Applications in catalysis, separation, adsorption, immobilization of enzymes, transport and controlled release of drugs, and nanotechnology, as suitable matrices for preparation of nanoparticles of advanced materials, are naturally areas of interest [7-16].

The copolymer F127 when used as a structure modifier serves to produce pores in the silica gels, not only with an ordered porous structure, but with possibility of formation of various pore classes in the gel. This copolymer also allows one to obtain pores with characteristic size greater than those generated by surfactants of smaller molecular weight.

The sol-gel process allows one to obtain silica particles of different sizes through the variation of reaction parameters as temperature, $\mathrm{pH}$, reactant concentration, type and concentration of catalyst, etc. The chemical nature of the particle surface can also be tailored in the sol-gel process. The sol-gel process of silicon alkoxides and the chemistry

\footnotetext{
* Corresponding author. Tel.: +55 19 35269183; fax:+55 1935269179.

E-mail address: fabiosv@rc.unesp.br (F.S. de Vicente).
} 
involved in the process lead to a more control of the purity of the final products.

The system silica/surfactant has attracted the attention of researchers in the material area due to the facility in obtaining mesoporous silica gels. This is due to the fact that the surfactant molecules form micelles in acids solutions, which can be cylindrical, spherical or lamellar, depending on the synthesis conditions [17], constituting a wide range of structural possibilities in the gel formation. In this work, copolymer F127 was used as an impregnate structure agent and HMDZ as a silylation agent in the obtaining of hydrophobic ambient pressure drying aerogels. The results were analyzed by small-angle X-ray scattering (SAXS), nitrogen adsorption and thermogravimetric analysis.

\section{Material and methods}

A starting F127 solution was prepared by dissolving $4.0 \mathrm{~g}$ of copolymer Pluronic F127 in $30 \mathrm{ml}$ of water and $120 \mathrm{ml}$ of $\mathrm{HCl} 2 \mathrm{M}$, under mechanical stirring for $20 \mathrm{~h}$ at ambient temperature. Sols of silica were prepared from hydrolysis of a fixed amount of $25 \mathrm{ml}$ of TEOS and $8 \mathrm{ml}$ of water mixed to different quantities of the F127 solution $(0,10,20$ and $30 \mathrm{ml}$ ) to yield silica sols with different concentrations of F127. The hydrolysis was carried out under mechanical stirring at $35^{\circ} \mathrm{C}$ for $60 \mathrm{~min}$ in reflux conditions. The resultant sols were cast in sealed plastic containers for gelation followed by aging for 15 days at $40^{\circ} \mathrm{C}$ to obtain very consolidate monolithic wet gels. The wet gels were washed in ethanol to remove the F127 to yield the washed wet samples named T0, T10, T20, and T30, associated respectively with the volumes $0,10,20$ and $30 \mathrm{ml}$ of the F127 solution used in the preparation of the gels. The wet gels T0, T10, T20, and T30 were studied by SAXS.

Aerogels were prepared by ambient pressure drying (APD), after silylation of the surface of the silica particles of the gels T0, T10, T20, and T30 with a solution of $20 \% \mathrm{v} / \mathrm{v}$ of the HMDZ (Sigma-Aldrich, 99\%) in $n$-hexane. This procedure yields the set of APD aerogels AF0, AF10, AF20, and AF30, from the set T0, T10, T20, and T30, respectively. Samples of these aerogels were heated with a heating rate of $10{ }^{\circ} \mathrm{C} / \mathrm{min}$ and kept for $4 \mathrm{~h}$ at $300,500,700$ and $900^{\circ} \mathrm{C}$. The aerogels were degassed at $120^{\circ} \mathrm{C}$ for $24 \mathrm{~h}$ prior to measurements of SAXS and nitrogen adsorption.

Small-angle X-ray scattering (SAXS) patterns was carried out using synchrotron radiation with a wavelength $\lambda=0.1608 \mathrm{~nm}$ at the SAXS beam line of the National Synchrotron Light Laboratory (LNLS), Campinas, Brazil. The beam was monochromatized by a silicon monochromator and collimated by a set of slits defining pinhole geometry. A 2D position sensitive X-ray detector was used to obtain isotropic SAXS intensity $I(q)$ as a function of the modulus $q=(4 \pi / \lambda) \sin$ $(\theta / 2)$ of the scattering vector, where $\theta$ is the scattering angle. The coherent scattering data (the incoherent scattering is neglected at small angle) were corrected by sample attenuation and parasitic scattering (the scattering produced without the sample in the same experimental conditions). No additional background correction was carried out in the SAXS data of the wet gels (neither even of the aerogels) because the scattering from the silica particles is much more intense than the background produced by the solvent (essentially ethanol at this stage of the wet gels). The solvent background correction could be critical in polymeric organic systems (as soft resorcinol-formaldehyde polymer gels) [18] because the electronic density contrast between the organic polymeric matrix and the solvent is not too large.

Nitrogen adsorption isotherms were obtained at liquid nitrogen temperature $(77 \mathrm{~K})$, using a Micromeritics ASAP 2010 equipment. The specific surface area $S_{\mathrm{BET}}$ was determined using the BET method. The total pore volume per mass unit $V_{\mathrm{p}}$ was measured as the total volume of nitrogen adsorbed at a point close to the nitrogen saturation pressure. The mean pore size $l_{\mathrm{p}}$ was evaluated as $l_{\mathrm{p}}=4 V_{\mathrm{p}} / S_{\text {BET }}$. Thermogravimetric analysis was carried out in atmospheric conditions with a heating rate of $10^{\circ} \mathrm{C} / \mathrm{min}$, using a Shimadzu Thermal Analyzer TA50 equipment.
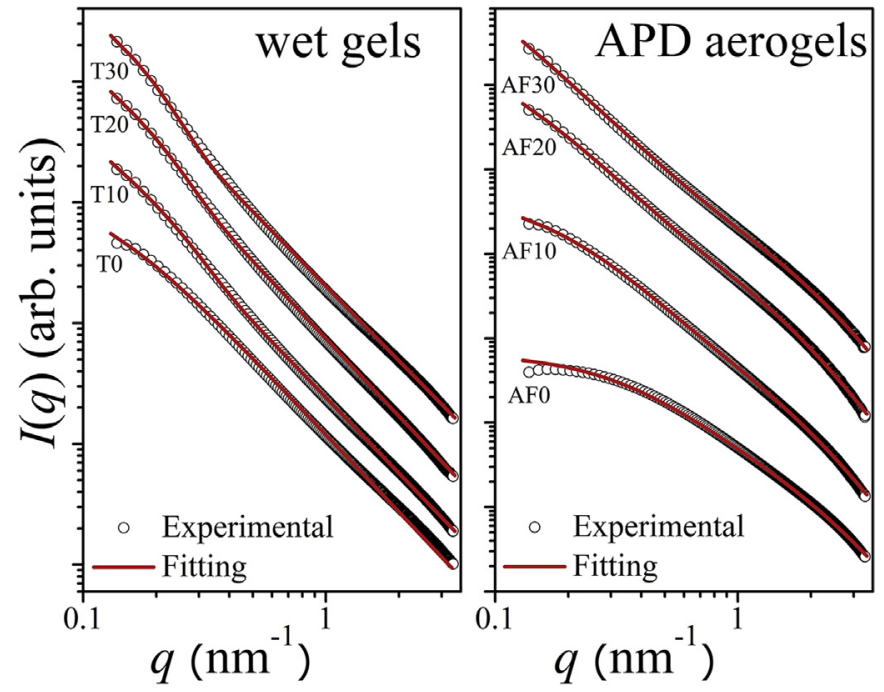

Fig. 1. (on the left) SAXS intensity of the wet gels prepared from hydrolysis of TEOS in different concentrations of the copolymer Pluronic F127. (on the right) SAXS intensity of the APD aerogels after silylation using HMDZ and ambient pressure drying (APD).

\section{Results and discussion}

\subsection{Wet gels}

Fig. 1 (on the left) shows the SAXS intensity $I(q)$ as a function of the modulus $q$ of the scattering vector for the wet gels T0, T10, T20 and T30. The curve of the wet gel T0 can be associated with that produced by a system of mass-fractal clusters. The mass of a mass-fractal cluster scales with the length scale $r$ as $m(r) \propto r^{D}$ in an interval $\xi \gg r \gg r_{0}$, where $\xi$ is the characteristic length of the mass-fractal domain formed by primary particles of characteristic size $r_{0}$, and $D$ is the dimension of the mass-fractal structure, a value in the range $1<D<3$. The scattering intensity $I(q)$ from such a system is a power-law on the reciprocal space $q$, within the interval $\xi^{-1} \ll q \ll r_{0}{ }^{-1}$, so that

$I(q) \propto q^{-D}$.

$I(q)$ deviates from the power-law of eq (1) at low- $q$, at about $q \sim 1$ / $\xi$, due to the finite size $\xi$ of the characteristic size of the cluster, and at high- $q$, at about $q \sim 1 / r_{0}$, due to the finite size $r_{0}$ of the primary particle building up the mass-fractal structure [19]. The effects of the cut-offs at low- $q(\sim 1 / \xi)$ and high- $q\left(\sim 1 / r_{0}\right)$ have been treated by Freltof et al. [20] and Teixeira [21] and the results could be resumed in following equation

$I(q)=A\left[1 /\left(1+r_{0}^{2} q^{2}\right)^{2}\right]\left[1+B \Gamma(D+1) \sin [(D-1) \arctan (q \xi)] /\left(1+q^{2} \xi^{2}\right)^{(D-1) / 2}(D-1) q \xi\right]$,

where $A$ and $B$ are constants, $\left[1 /\left(1+r_{0}^{2} q^{2}\right)^{2}\right]=P(q)$ is Debye-Bueche form and represents the scattering from a isolate primary particle, and the last term in the brackets represents the interference function $S(q)$ between the scattering from all primary particles forming a cluster of characteristic size $\xi$ and fractal dimension $D$.

The SAXS pattern of the sample T0 [Fig. 1 (on the left)] exhibits a crossover at low- $q$ but no crossover at high- $q$, meaning that the characteristic size $\xi$ of the cluster could be resolved but the characteristic size $r_{0}$ of the primary particle could not be resolved, since the high- $q$ crossover $\left(\sim 1 / r_{0}\right)$ would be above $q_{\mathrm{m}} \sim 3.34 \mathrm{~nm}^{-1}$, being $q_{\mathrm{m}}$ the maximum experimentally accessible value for $q$ in this experimental setup. When $r_{0} \ll 1 / q_{\mathrm{m}} \sim 0.3 \mathrm{~nm}$, the scattering from the primary particle $P(q)$ can be considered constant in the range $q_{0}<q<q_{\mathrm{m}}$, so that no crossover appears at high- $q$ and the term 1 of the interference function $S(q)$ can be neglected in comparison with the second one, so eq 
Table 1

SAXS structural parameters of the wet gels.

\begin{tabular}{llll}
\hline Sample & $\xi(\mathrm{nm})$ & $D$ & $R_{\mathrm{g}}(\mathrm{nm})$ \\
\hline T0 & $9.1(1)$ & $2.12(2)$ & - \\
T10 & - & $2.08(2)$ & $9.02(8)$ \\
T20 & - & $2.13(2)$ & $10.1(1)$ \\
T30 & - & $2.05(2)$ & $11.8(1)$ \\
\hline
\end{tabular}

Numbers in brackets represent errors in the last of the significant figures.

The same applies to other Tables in the text.

(2) could be approximated by

$I(q)=C \Gamma(D+1) \sin [(D-1) \arctan (q \xi)] /\left[\left(1+q^{2} \xi^{2}\right)^{(D-1) / 2}(D-1) q \xi\right]$,

where $C$ is a constant. Eq (3) has a crossover at low- $q$ defined by the parameter $\xi$ and tends to the power-law $I(q) \propto q^{-D}$ [eq (1)] at intermediary- and high- $q$ values, which leads to the exponent $D$. The parameters $\xi$ and $D$ were obtained (Table 1 ) by fitting eq (3) to the experimental data of the sample T0.

The characteristic size $\xi$ of the fractal domain of the sample T0 $(\sim 9.5 \mathrm{~nm})$ was found not very far from the order fairly allowed by low$q$ limit of the present experimental setup $\left(1 / q_{0} \sim 7.3 \mathrm{~nm}\right)$. With the additions of F127, the mass-fractal domain size $\xi$ grows further of this experimental measurable max limit, so the power-law behavior $I(q) \propto q^{-D}$ [eq (1)] extrapolates the experimental low- $q$ limit $\sim 1 / q_{0}$, so the parameter $\xi$ could not be determined. Besides that, for the samples T10, T20 and T30, an additional contribution to the scattering seems to superpose that of the fundamental mass fractal scattering $\left[I(q) \propto q^{-D}\right]$ at low- $q$ shown in Fig. 1. Assuming that such an additional contribution could be described as the scattering from a homogenous particle with radius of gyration $R_{\mathrm{g}}$, like as larger pores embedded in the fractal structure originated by the F127 removal, for which the Guinier law applies, thus the resulting scattering intensity could be fitted by the equation

$I(q)=G \exp \left(-R_{g}^{2} q^{2} / 3\right)+F q^{-D}$,

where $G$ and $F$ are constants. Table 1 shows the fitted parameters $R_{\mathrm{g}}$ and $D$ for the samples T10, T20 and T30.

\subsection{APD aerogels}

3.2.1. SAXS

Fig. 1 (on the right) shows the SAXS patterns obtained for the set of APD aerogels AF0, AF10, AF20 and AF30 prepared by silylation with HMDZ.

The SAXS curves of the APD aerogels [Fig. 1 (on the right)] differ from those of the wet gels [Fig. 1 (on the left)] mainly by the presence of a crossover at high- $q$, characterizing the development of a primary particle with finite size $r_{0}>\sim 1 / q_{\mathrm{m}} \sim 0.3 \mathrm{~nm}$, along the process of the aerogel obtaining. The SAXS curves of the APD aerogels also differ at low- $q$ from those of the wet gels, since the earlier additional contribution due to the presence of larger pores with radius of gyration $R_{\mathrm{g}}$ (formed by the F127 removal) disappears, while the characteristic size $\xi$ diminishes, since the low- $q$ crossover $\sim 1 / \xi$ shifts towards larger values of $q$ as the concentration of F127 increases. As a matter of fact, for the sample AF30, the intensity at low- $q$ is a power-law $I(q) \propto q^{-D}$ which extrapolates the experimental limit $q_{0}$ towards the low- $q$ region, meaning that $\xi$ could not be determined and no additional effect due to larger pores with $R_{\mathrm{g}}$ is apparent. These modifications could be explained by postulating that some porosity elimination occurred by the overall process of silylation and ambient pressure drying. Coherently, the SAXS intensity from the samples AF0, AF10 and AF20 were fitted by eq (2), resolving for $\xi, D$ and $r_{0}$, and that from the sample AF30, resolving for $D$ and $r_{0}$, by the equation
Table 2

SAXS structural parameters of the APD aerogels.

\begin{tabular}{llll}
\hline Sample & $\xi(\mathrm{nm})$ & $D$ & $r_{0}(\mathrm{~nm})$ \\
\hline AF0 & $3.07(4)$ & $2.10(7)$ & $0.41(2)$ \\
AF10 & $5.69(5)$ & $2.44(3)$ & $0.66(3)$ \\
AF20 & $10.8(1)$ & $2.50(3)$ & $0.79(3)$ \\
AF30 & - & $2.50(3)$ & $0.61(3)$ \\
\hline
\end{tabular}

$I(q)=A\left[1 /\left(1+q^{2} r_{0}^{2}\right)^{2}\right]\left[1+F^{\prime} q^{-D}\right]$,

where $F^{\prime}$ is a constant. Eq (5) is analogous to eq (2) except by the high- $q$ crossover that has not been neglected here by keeping the interference function as $S(q)=\left[1+F^{\prime} q^{-D}\right]$, so that the term 1 could not be neglected in comparison with $F^{\prime} q^{-D}$ at high- $q$ and $S(q) \approx F^{\prime} q^{-D}$ at lowand intermediary- $q$. Table 2 shows the parameters fitted for the APD aerogels.

The overall process of ambient pressure drying reduces the characteristic size $\xi$ of the mass-fractal clusters of the aerogels and increases the characteristic size $r_{0}$ of the primary particles building up the clusters (Table 2), with respect to the corresponding values of the wet gels (Table 1). The mass-fractal dimension $D$ of the aerogels prepared with additions of F127 (Table 2) exhibited values significantly larger than those corresponding of wet gels (Table 1). The aerogel prepared without addition of F127 (AF0) presented approximately the same value for the mass-fractal dimension $D$ as that of the corresponding wet gel (Table 1), however, the mass-fractal range $\left[1 / \xi<q<1 / r_{0}\right]$ was found much more narrowed and ill-defined in the aerogel AF0. These aspects demonstrate that the ambient pressure drying tends to compress the mass-fractal structure, reducing $\xi$ and increasing $r_{0}$, and eliminating most of the larger pores of radius of gyration $R_{\mathrm{g}}$ formed by the F127 removal, or at least bringing them into the mass-fractal range in the aerogels. In the case of the aerogels prepared with additions of F127 (AF10, AF20, AF30), the ambient pressure drying increases the massfractal dimension $D$ (Table 2) with respect to the corresponding wet gels (Table 1 ) and brings the characteristic size $\xi$ [not defined in the wet gels (Table 1)] into the apparent mass-fractal range of the aerogels, emphasizing the compressing effect of the ambient pressure drying on the mass-fractal structure.

\subsubsection{Nitrogen adsorption}

Fig. 2 (on the left) shows the isotherms of nitrogen adsorption for the aerogels prepared with different concentrations of F127 by silylation with HMDZ. The isotherms can all be classified as being of the type IV in the general IUPAC classification [22], compatible with mesoporous solids.

Table 3 shows the experimental values for the specific surface area $S_{\mathrm{BET}}$, the total pore volume per mass unit $V_{\mathrm{p}}$, and the mean pore size $l_{\mathrm{p}}$ obtained from the isotherms in Fig. 3. Table 3 also shows the estimated values for the nitrogen bulk density $\rho_{\mathrm{N} 2}$, the mean silica particle size $l_{\mathrm{S}}$, and the porosity $\phi$ for the aerogels, as evaluated through the relationships $\left(1 / \rho_{\mathrm{N} 2}\right)=\left(1 / \rho_{\mathrm{S}}\right)+V_{\mathrm{p}}, l_{\mathrm{S}}=4 / \rho_{\mathrm{S}} S_{\mathrm{BET}}$, and $\phi=\left(\rho_{\mathrm{s}}-\rho_{\mathrm{N} 2}\right) / \rho_{\mathrm{S}}$, where $\rho_{\mathrm{S}}$ is the aerogel skeleton density, assumed as the fused silica density $\left(2.2 \mathrm{~g} / \mathrm{cm}^{3}\right)$. The skeleton density could be minor than that assumed $\left(2.2 \mathrm{~g} / \mathrm{cm}^{3}\right)$, since the hydrophobic aerogels normally contain a percentage of carbon that could reduce the skeleton density up to values between 1.8 and $2.0 \mathrm{~g} / \mathrm{cm}^{3}$. However, the assumption of $\rho_{\mathrm{S}}=2.2 \mathrm{~g} / \mathrm{cm}^{3}$ is not so critical, since, for instance, the use of $\rho_{\mathrm{S}}=1.8 \mathrm{~g} / \mathrm{cm}^{3}$ instead causes only a diminution between 3 and $6 \%$ in the values estimated for $\rho_{\mathrm{N} 2}$ in Table 3 .

The values of the specific surface area $S_{\mathrm{BET}}$ measured for the APD aerogels were found about $800 \mathrm{~m}^{2} / \mathrm{g}$. This is a typical value found in aerogels prepared by supercritical process. The pore volume $V_{\mathrm{p}}$ and the mean pore size $l_{\mathrm{p}}$ increase regularly with increasing the amount of F127. The mean silica particle size $l_{S}$ increases accompanying the slight diminishing of $S_{\mathrm{BET}}$ with increasing the concentration of F127, in 

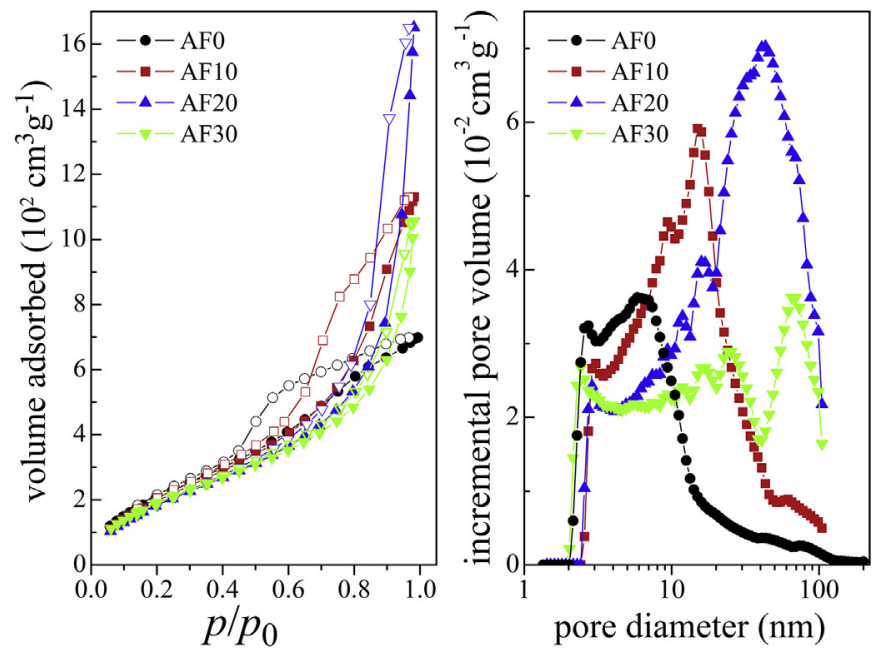

Fig. 2. (on the left) Nitrogen adsorption isotherms for APD aerogels, prepared with different F127 concentrations, after silylation with HMDZ. Open symbols mean desorption branch. (on the right) Pore size distribution for the APD aerogels.

Table 3

Structural parameters of the aerogels from nitrogen adsorption isotherms.

\begin{tabular}{lllllll}
\hline Sample & $S_{B E T}\left(\mathrm{~m}^{2} / \mathrm{g}\right)$ & $V_{p}\left(\mathrm{~cm}^{3} / \mathrm{g}\right)$ & $l_{p}(\mathrm{~nm})$ & $l_{s}(\mathrm{~nm})$ & $\rho_{N 2}(\mathrm{~g} . \mathrm{cm}-3)$ & $\phi(\%)$ \\
\hline AF0 & $844(5)$ & $1.08(2)$ & $5.1(4)$ & $2.1(1)$ & $0.65(2)$ & $70(1)$ \\
AF10 & $823(5)$ & $1.73(3)$ & $8.4(2)$ & $2.2(1)$ & $0.46(2)$ & $79(1)$ \\
AF20 & $765(6)$ & $2.44(2)$ & $12.7(5)$ & $2.4(1)$ & $0.34(2)$ & $85(1)$ \\
AF30 & $773(5)$ & $1.55(2)$ & $8.1(3)$ & $2.3(1)$ & $0.50(2)$ & $77(1)$ \\
\hline
\end{tabular}

accordance with the increase of the parameter $r_{0}$ as observed by SAXS (Table 2). The irregular decrease of $V_{\mathrm{p}}$ and $l_{\mathrm{p}}$ in the sample AF30 was assigned to the measurable maximum limit for the pore size associated to the nitrogen absorption method.

The pore size distribution curves of the aerogels were determined by
Kelvin classical equation using Harkins and Jura isotherm for the adsorbed layer thickness and a model of cylindrical pores [22]. Fig. 2 (on the right) shows de pore size distribution for the APD aerogels silylated by HMDZ. The pore size distribution of the aerogels widens while the maximum in the pore size distribution shifts towards the macropore region with increasing of the F127 concentration. For instance, the pore size distribution exhibits a maximum at $\sim 7 \mathrm{~nm}$ for the pure sample $\mathrm{AF} 0, \sim 15 \mathrm{~nm}$ for AF10, $\sim 40 \mathrm{~nm}$ for AF20, and the maximum is clearly beyond the measurable maximum limit of pore size probed by nitrogen absorption method for the sample AF30. As a matter of fact, the isotherm of the sample AF30 in Fig. 2 (on the left) was found rising up at higher $p / p_{0}$ with respect to the other samples. It has been pointed that conventional nitrogen adsorption can underestimate the pore volume in a sparse silica network, because the adsorbate/vapor interface can assume a surface of zero curvature before much of the larger pores could be fulfilled [23,24], or even because compliant samples, as sparse silica networks, could contract upon nitrogen sorption analysis [25].We do not think that silylated aerogels could contract easily upon nitrogen sorption, so the apparent underestimation of the pore volume in the sample AF30 should be due to the adopted zero curvature of the adsorbate/vapor interface before larger pores could be filled. However, we wish to emphasize that the results of the pore structure characterization by nitrogen adsorption for the samples AF0, AF10, and AF20, for which it seem there be a typical mesoporosity well defined, are very consistent among them and qualitatively in good agreement with the SAXS data.

We wish yet to point that the variation of the structural properties of the aerogels (and also by correlation of the wet gels) observed with the additions of F127, mainly the properties related with the pore volume $V_{\mathrm{p}}$, could well have a component due the silica dilution effect, since the volume of the F127 solution has been gradually increased in the preparation of the samples to vary the F127 concentration. However, we have reasons to claim that the silica dilution has a minor effect on the pore structure compared to that due to the addition of the polymer in the present system. The main reason resides in the fact that it was already studied the effects of additions of (i) a similar polymeric surfactant (P123) [26] and (ii) a micellar system (sodium dodecyl sulfate)
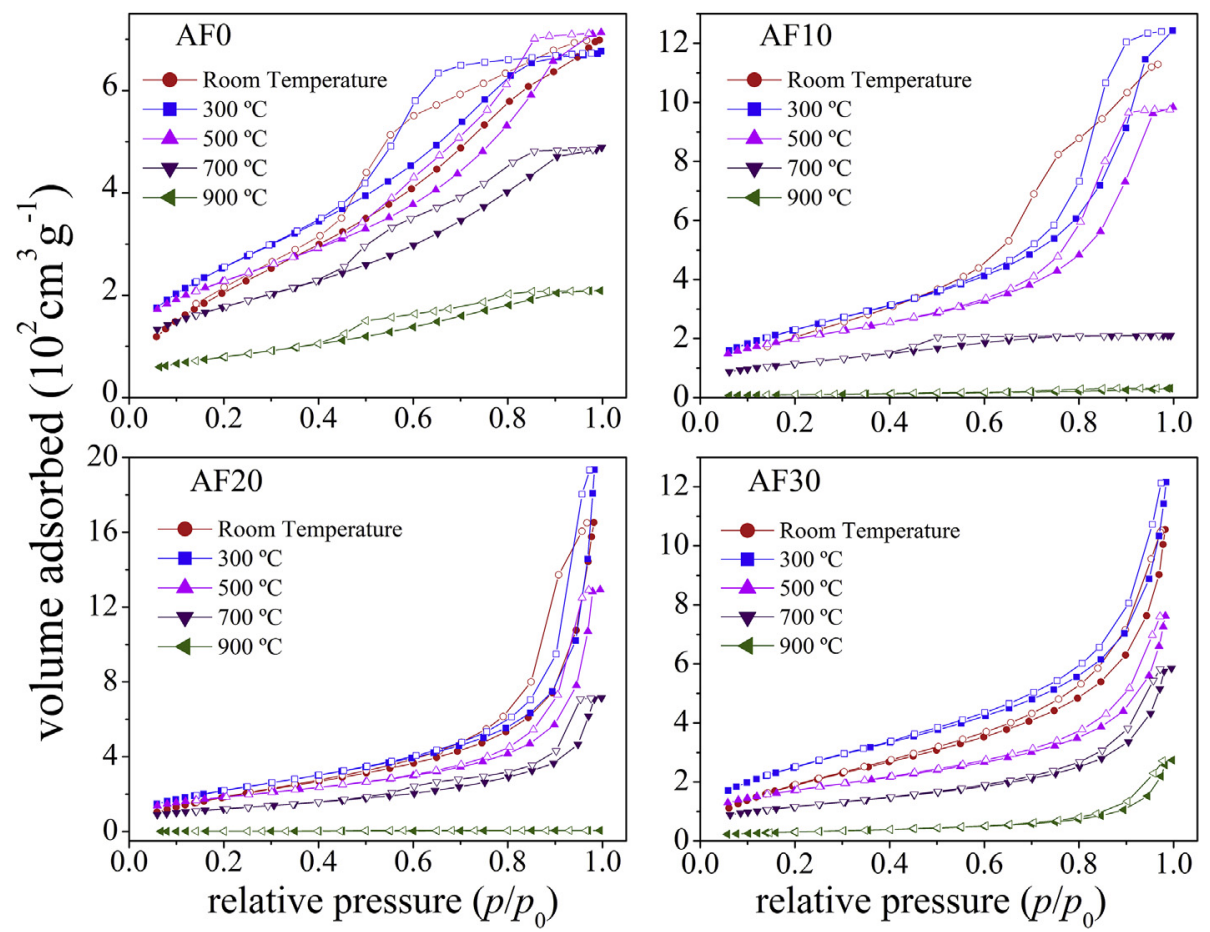

Fig. 3. Nitrogen adsorption isotherms for APD aerogels after heat treatment at $300{ }^{\circ} \mathrm{C}, 500{ }^{\circ} \mathrm{C}, 700{ }^{\circ} \mathrm{C}$ and $900{ }^{\circ} \mathrm{C}$. Open symbols mean desorption branch. 
Table 4

Structural parameters of the aerogels from nitrogen adsorption isotherms after heat treatment.

\begin{tabular}{|c|c|c|c|c|c|c|c|}
\hline Sample & $T\left({ }^{\circ} \mathrm{C}\right)$ & $\begin{array}{l}S_{\mathrm{BET}} \\
\left(\mathrm{m}^{2} / \mathrm{g}\right)\end{array}$ & $V_{\mathrm{p}}\left(\mathrm{cm}^{3} / \mathrm{g}\right)$ & $l_{\mathrm{p}}(\mathrm{nm})$ & $l_{\mathrm{S}}(\mathrm{nm})$ & $\begin{array}{l}\rho_{\mathrm{N} 2}(\mathrm{~g} / \\
\left.\mathrm{cm}^{3}\right)\end{array}$ & $\phi(\%)$ \\
\hline \multirow[t]{5}{*}{ AF0 } & Ambient & 844 (5) & $1.08(2)$ & $5.1(4)$ & $2.1(1)$ & $0.65(2)$ & $70(1)$ \\
\hline & $300^{\circ} \mathrm{C}$ & 960 (5) & $1.04(2)$ & $4.3(3)$ & $1.9(1)$ & $0.67(2)$ & 69 (1) \\
\hline & $500^{\circ} \mathrm{C}$ & 830 (4) & $1.10(2)$ & $5.3(5)$ & $2.2(1)$ & 0.64 (2) & $71(1)$ \\
\hline & $700^{\circ} \mathrm{C}$ & 647 (4) & $0.76(2)$ & $4.7(4)$ & $2.8(1)$ & $0.82(2)$ & $63(2)$ \\
\hline & $900^{\circ} \mathrm{C}$ & $292(5)$ & $0.32(2)$ & $4.4(4)$ & $6.2(1)$ & 1.29 (4) & $41(2)$ \\
\hline \multirow[t]{5}{*}{ AF10 } & Ambient & $823(5)$ & 1.73 (3) & $8.4(2)$ & $2.2(1)$ & $0.46(2)$ & $79(1)$ \\
\hline & $300{ }^{\circ} \mathrm{C}$ & $871(5)$ & $1.92(2)$ & $8.8(4)$ & $2.1(1)$ & $0.42(2)$ & $81(1)$ \\
\hline & $500^{\circ} \mathrm{C}$ & 727 (4) & $1.52(2)$ & $8.4(5)$ & $2.5(1)$ & 0.51 (2) & 77 (1) \\
\hline & $700^{\circ} \mathrm{C}$ & $421(4)$ & $0.32(3)$ & $3.1(4)$ & $4.3(2)$ & 1.29 (4) & $41(2)$ \\
\hline & $900{ }^{\circ} \mathrm{C}$ & $35(5)$ & $0.05(2)$ & $5.3(8)$ & $52(3)$ & $1.98(7)$ & $10(2)$ \\
\hline \multirow[t]{5}{*}{ AF20 } & Ambient & $765(6)$ & $2.44(2)$ & $12.7(5)$ & $2.4(1)$ & $0.34(2)$ & $85(1)$ \\
\hline & $300{ }^{\circ} \mathrm{C}$ & 842 (5) & $2.80(2)$ & $13.3(5)$ & $2.1(1)$ & $0.31(2)$ & $86(1)$ \\
\hline & $500^{\circ} \mathrm{C}$ & 675 (5) & $1.98(2)$ & $11.8(5)$ & $2.7(2)$ & 0.41 (2) & $81(1)$ \\
\hline & $700{ }^{\circ} \mathrm{C}$ & $446(4)$ & $1.10(3)$ & $9.8(4)$ & $4.0(3)$ & 0.64 (4) & $71(2)$ \\
\hline & $900^{\circ} \mathrm{C}$ & $7(2)$ & 0.01 (1) & $5(5)$ & $257(60)$ & $2.15(7)$ & $2(2)$ \\
\hline \multirow[t]{5}{*}{ AF30 } & Ambient & 773 (5) & $1.55(2)$ & $8.1(3)$ & $2.3(1)$ & $0.50(2)$ & 77 (1) \\
\hline & $300{ }^{\circ} \mathrm{C}$ & 949 (5) & 1.77 (2) & $7.5(5)$ & $1.9(1)$ & $0.45(2)$ & $80(1)$ \\
\hline & $500^{\circ} \mathrm{C}$ & $623(5)$ & $1.12(2)$ & $7.2(5)$ & $2.9(3)$ & $0.64(2)$ & $71(1)$ \\
\hline & $700^{\circ} \mathrm{C}$ & $424(4)$ & 0.89 (3) & $8.4(5)$ & $4.3(4)$ & 0.74 (4) & $66(2)$ \\
\hline & $900{ }^{\circ} \mathrm{C}$ & $111(6)$ & $0.42(2)$ & 14 (1) & $16(2)$ & 1.17 (5) & $47(4)$ \\
\hline
\end{tabular}

[27] in the preparation of APD aerogels, starting from samples prepared with essentially the same silica concentration. The results with respect to the variation of the pore volume as a function of the additions of the surfactants were found very similar to the present study. We think the effect of silica dilution on the porosity is somewhat mitigated in the present system because the syneresis degree increases with the silica dilution, while the wet gels are kept embedded in water for consolidation before the polymer washing.

\subsubsection{Heat treatment - nitrogen adsorption}

Fig. 3 shows the nitrogen adsorption isotherms for the aerogels AF0, $\mathrm{AF} 10, \mathrm{AF} 20$ and $\mathrm{AF} 30$ heat treated at $300^{\circ} \mathrm{C}, 500{ }^{\circ} \mathrm{C}, 700^{\circ} \mathrm{C}$ and $900{ }^{\circ} \mathrm{C}$. The isotherms can be classified in the general as that of the type IV, compatible with mesoporous solids. Table 4 shows the experimental values of $S_{\mathrm{BET}}, V_{\mathrm{p}}$, and $l_{\mathrm{p}}$ together with the estimated values of $\rho_{\mathrm{N} 2}, l_{\mathrm{S}}$, and $\phi$ for this set of heat treated APD aerogels.

Table 4 shows that, in the general, the specific surface area $S_{\mathrm{BET}}$ and the pore volume $V_{\mathrm{p}}$ varied only discretely by heat treating up to about $500{ }^{\circ} \mathrm{C}$. Indeed, $S_{\mathrm{BET}}$ and $V_{\mathrm{p}}$ first increased a few at $300^{\circ} \mathrm{C}$, with respect to the values observed at room temperature, and decreased again at $500{ }^{\circ} \mathrm{C}$. The slight increase of $S_{\mathrm{BET}}$ and $V_{\mathrm{p}}$ in the sample treated at $300{ }^{\circ} \mathrm{C}$ was attributed to the thermal elimination of eventual residual F127, since the burning of the silylated layer seems to occur only at about $350^{\circ} \mathrm{C}$, according to the thermogravimetric study presented in the next section. As a matter of fact, the sample treated at $300{ }^{\circ} \mathrm{C}$ has kept its hydrophobicity, while those treated at $500{ }^{\circ} \mathrm{C}$ and above have lost their hydrophobicity. This matter will be better addressed in the next section together with the thermogravimetric study. The diminution of the mean particle size $l_{\mathrm{S}}$ at $300^{\circ} \mathrm{C}$ with respect to the sample at room temperature (Table 4) is also compatible with the thermal elimination of residual F127. $S_{\mathrm{BET}}$ and $V_{\mathrm{p}}$ diminished drastically by heat treating at $700{ }^{\circ} \mathrm{C}$ and, in the general, they were found almost vanished at $900^{\circ} \mathrm{C}$, mainly for the samples prepared with F127. This may mean that the porosity in the samples originated by the copolymer F127 could be more easily eliminated by heat treatment, in comparison with the sample prepared without F127.

The mean pore size $l_{\mathrm{P}}$ was found varying slightly up to about $500{ }^{\circ} \mathrm{C}$ and, in the general, it diminishing drastically with increasing temperature by heat treatment at higher temperatures, except for the sample AF30 treated a $900{ }^{\circ} \mathrm{C}$, for which a high value $(\sim 14 \mathrm{~nm})$ for $l_{\mathrm{p}}$ have been found. This may mean the actuation of a mechanism of pore elimination starting preferentially by the smaller ones.

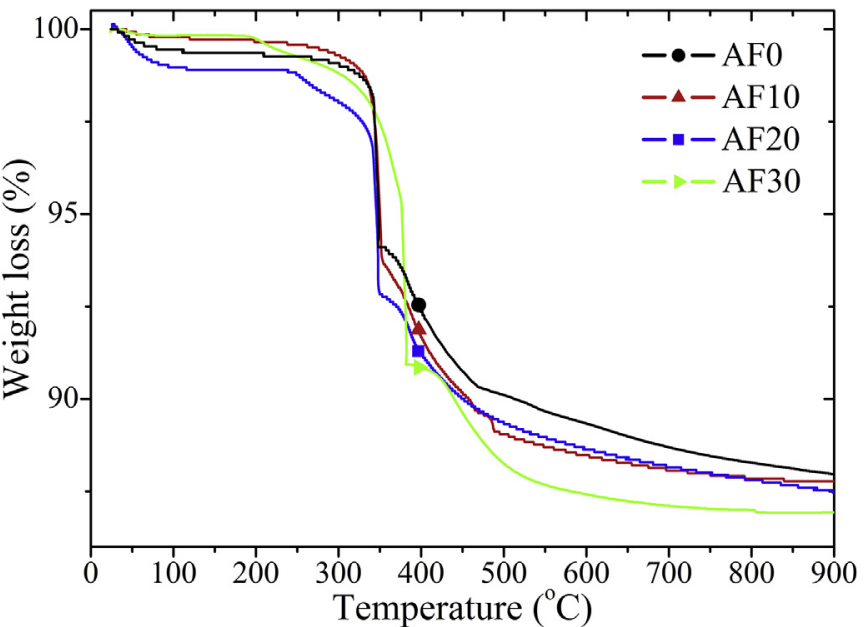

Fig. 4. Thermogravimetric analysis for the APD aerogels carried out in conditions of synthetic air with a heating rate of $10^{\circ} \mathrm{C} / \mathrm{min}$.

\subsubsection{Thermogravimetric study}

Fig. 4 shows the thermogravimetric analysis (TGA) as a temperature function carried out for the APD aerogels in synthetic air conditions with a heating rate of $10{ }^{\circ} \mathrm{C} / \mathrm{min}$. The general characteristics of the TGA curves in Fig. 4 are: (i) some mass loss below about $300{ }^{\circ} \mathrm{C}$; (ii) a very sharp (practically vertical) mass loss at about $350{ }^{\circ} \mathrm{C}\left(\sim 370^{\circ} \mathrm{C}\right.$ for the sample AF30); (iii) and a gradual mass loss starting practically with zero mass loss rate just after the sharp second event, going asymptotically up to about $900{ }^{\circ} \mathrm{C}$. The first event was found more intense for the samples prepared with F127 and it was attributed to the thermal elimination of some residual F127 eventually remnant from the washing processing. The second and extremely abrupt event at about $350{ }^{\circ} \mathrm{C}$, detailed in Fig. 5 , involves a quantity of about $4.4 \%$ of mass loss (except for the sample AF10 for which it was found $\sim 4.9 \%$ ) and it was attributed to the burning and elimination of the organic part of the silylation layer on the silica surface. The third and asymptotic event was attributed to some elimination of eventual residual non hydrolyzed organic groups encrusted in the silica structure, eventually remnant from the early hydrolysis, and also to the very slow hydroxyl group elimination from the silica surface as a result of the surface (and pore) elimination with the heat treatment.

To assign the second and extremely sharp event at about $350{ }^{\circ} \mathrm{C}$ to the burning of organic part of the silylation layer we start concerning with the partially condensed silica species $\mathrm{SiO}_{3 / 2} \mathrm{OH}$ at the silica surface. The net result of the silylation process with HMDZ substitutes the hydrogen of the hydroxyl group by a group $-\mathrm{Si}\left(\mathrm{CH}_{3}\right)_{3}$, yielding a silytated surface layer which could be written as $\mathrm{SiO}_{3 / 2} \mathrm{O}-\mathrm{Si}\left(\mathrm{CH}_{3}\right)_{3}$. Then, the combustion reaction on such a surface could be written as

$\mathrm{SiO}_{3 / 2} \mathrm{O}-\mathrm{Si}\left(\mathrm{CH}_{3}\right)_{3}+12 \mathrm{O}_{2} \rightarrow \mathrm{SiO}_{2} \mathrm{SiO}_{3 / 2} \mathrm{OH}+3 \mathrm{CO}_{2}+4 \mathrm{H}_{2} \mathrm{O}$,

restoring the hydroxylated surface, so that the net mass loss at the silica surface would be equivalent to $3\left[\left(\mathrm{CH}_{3}\right)\right]-2[\mathrm{O}]-1[\mathrm{H}]$, which would give $\Delta m_{1}=12 \mathrm{~g} / \mathrm{mol}=2 \times 10^{-23} \mathrm{~g} / \mathrm{molecule}$. The cross section $\sigma$ of a silylated specie $-\mathrm{Si}\left(\mathrm{CH}_{3}\right)_{3}$ was estimated as $\sigma=\left[(1 / 2) V_{\mathrm{m}}\right]^{2 /}$ ${ }^{3}=22.1 \times 10^{-4} \mathrm{~m}^{2} / \mathrm{mol}=3.69 \times 10^{-19} \mathrm{~m}^{2} /$ molecule, where $V_{\mathrm{m}}$ is the HMDZ molar volume. Assuming a completely silylated surface with typically $S_{\mathrm{BET}}=800 \mathrm{~m}^{2} / \mathrm{g}$ (Table 3 ), we would have $N=S_{\mathrm{BET}}$ / $\sigma=2.17 \times 10^{21}$ molecule $/ g$ recovering the silica surface, yielding a total expected mass loss $\Delta m=N \Delta m_{1}=4.4 \times 10^{-2} \mathrm{~g} / \mathrm{g}=4.4 \%$.

This estimative is in good agreement with the mass variation associated with the extremely sharp (almost vertical) mass loss at about $350{ }^{\circ} \mathrm{C}(\sim 4.4 \%)$ found in the samples AF0 (prepared without F127), AF20, and AF30 (Fig. 5). The agreement is even not too bad for the sample AF10 ( $\sim 4.9 \%)$ if we realized that such an event was found more left-slanted (not so abrupt) in this sample, suggesting that the 

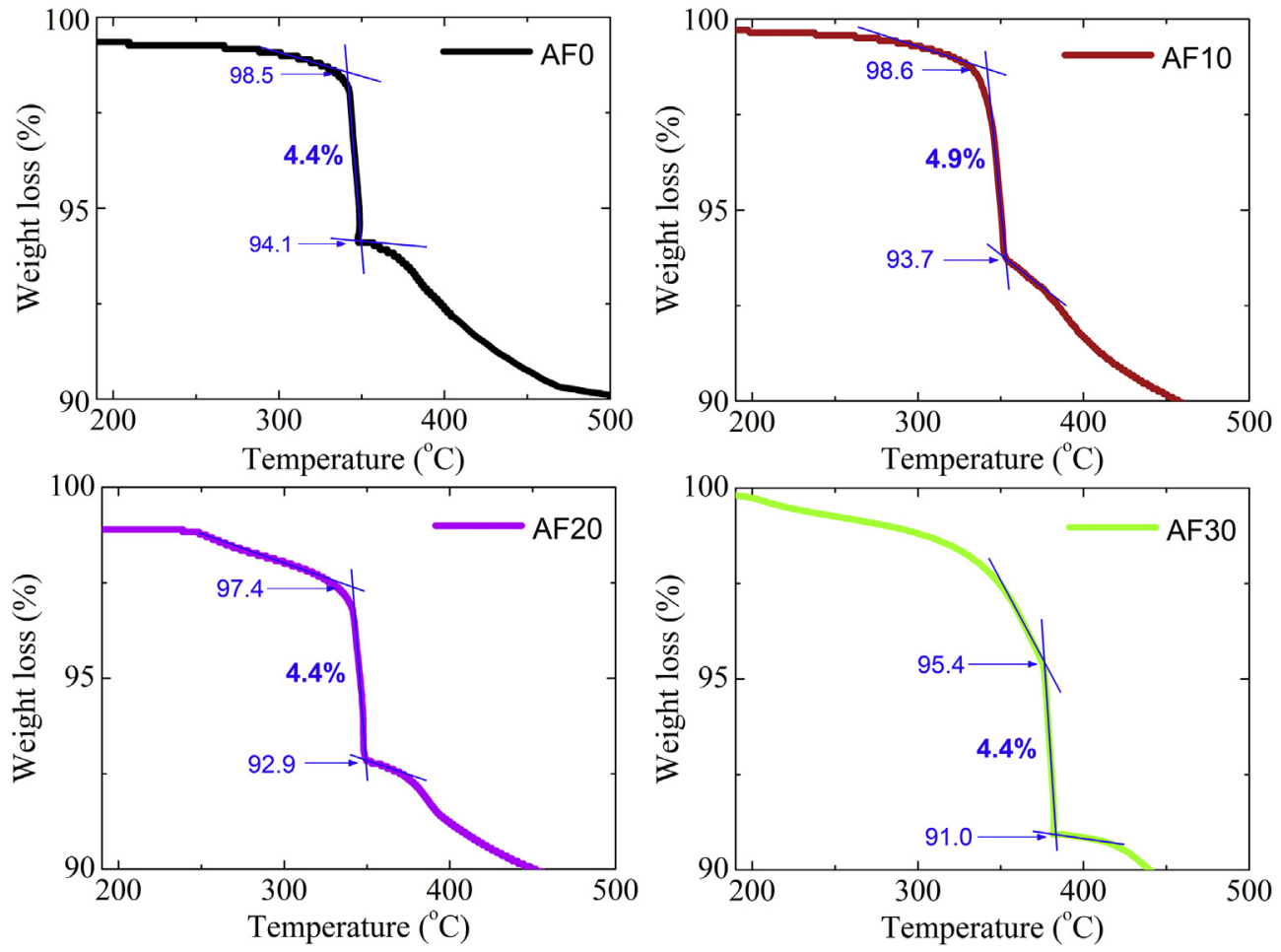

Fig. 5. Detailing of the abrupt mass loss found at about $350{ }^{\circ} \mathrm{C}$ for the APD aerogels.

elimination of the silylated alkyl groups $\left(-\mathrm{CH}_{3}\right)$ could be more smeared by some minor residual F127 elimination in this sample. The fact of the sample AF0 (prepared without F127) to exhibit a clear sharp mass loss of $4.4 \%$ at $350^{\circ} \mathrm{C}$ is a strong argument in favor of the elimination of the silylated groups $-\mathrm{CH}_{3}$, since there is no trace of polymer in this sample that could smear the signal of the elimination of $-\mathrm{CH}_{3}$. Such an event is extremely sharp because all groups $-\mathrm{CH}_{3}$ are equivalent and are burned in an analogy with a true phase transition in which the temperature is kept constant.

To better address the loss of the hydrophobicity by elimination of the groups $-\mathrm{CH}_{3}$ at about $350{ }^{\circ} \mathrm{C}$, monolithic samples of the aerogel AF20 were heat treated with a heating rate of $1{ }^{\circ} \mathrm{C} / \mathrm{min}$ and kept at $300{ }^{\circ} \mathrm{C}$ and $400{ }^{\circ} \mathrm{C}$ for $4 \mathrm{~h}$ under atmospheric conditions. Tests of hydrophobicity were carried out by dropping a water droplet $(\sim 3 \mathrm{~mm}$ diameter) on the surface of the monoliths. The water droplet did not wet the as-prepared sample (Fig. 6a), nor that treated at $300{ }^{\circ} \mathrm{C}$ (Fig. 6b), while the droplet was absorbed by the monolith treated at $400{ }^{\circ} \mathrm{C}$ (Fig. 6c), meaning complete loss of hydrophobicity.

\section{Conclusions}

Ambient pressure drying (APD) aerogels were prepared from the hydrolysis of tetraethylorthosilicate in water solutions of poly(ethylene oxide)-poly(propylene oxide)-poly(ethylene oxide) (F127), followed by silylation of the silica surface using a solution of $20 \%$ volume of hexamethyldisilazane (HMDZ) in n-hexane.
Wet gels can be described as mass-fractal structure, with massfractal dimension close to 2.1 and characteristic size $\xi$ spanning from about $9 \mathrm{~nm}$, for the gel prepared without F127, up to values that exceed the maximum limit allowed by experimental SAXS setup, for samples prepared with increasing quantity of F127. The addition of F127 also originated larger pores embedded in the mass-fractal structure of the wet gels, which were formed by the subsequent F127 removal.

The ambient pressure drying tends to compress the mass-fractal structure, reducing the characteristic size $\xi$ and increasing the characteristic size $r_{0}$ of primary particle of the fractal clusters, increasing in general the fractal dimension $D$, and eliminating most of the larger pores formed by the F127 removal. The specific surface area $S_{\mathrm{BET}}$ of the APD aerogels was found to be typically of about $800 \mathrm{~m}^{2} / \mathrm{g}$. This typical value diminished slightly with the concentration of F127, while the pore volume $V_{\mathrm{p}}$ and mean pore size $l_{\mathrm{p}}$ increased drastically with the concentration of F127.

Thermally treated APD aerogels showed a general similar behavior with the heat treatment temperature, independent of the concentration of F127. The porosity was found fairly stable up to about $500{ }^{\circ} \mathrm{C}$. The porosity started to be eliminated more effectively at $700^{\circ} \mathrm{C}$ and it was found practically collapsed at $900{ }^{\circ} \mathrm{C}$.

The organic groups $-\mathrm{CH}_{3}$ of the silylation layer on the silica surface of the present APD aerogels were promptly eliminated at about $350{ }^{\circ} \mathrm{C}$, losing completely their hydrophobicity.
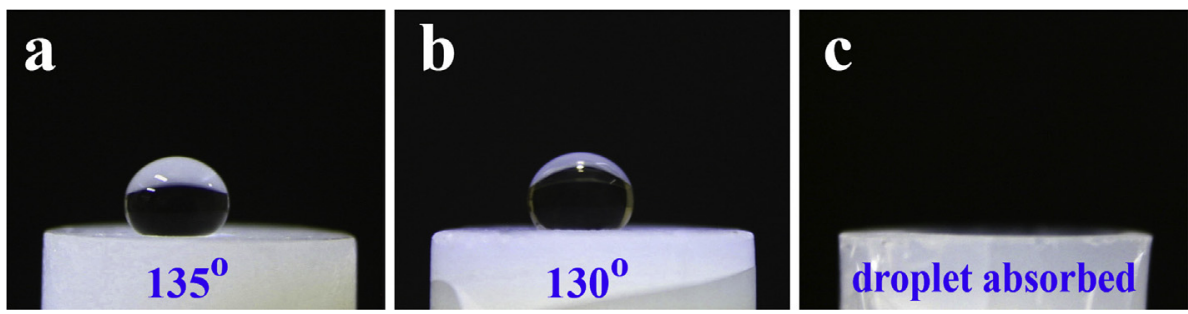

Fig. 6. Photograph of the monolithic aerogels after dropping a water droplet on the surface: a) as-prepared aerogel; b) aerogel treated at $300{ }^{\circ} \mathrm{C} / 4 \mathrm{~h}$ in air; c) aerogel treated at $400{ }^{\circ} \mathrm{C} / 4 \mathrm{~h}$ in air (in this case the droplet was absorbed by the aerogel meaning complete loss of hydrophobicity). The contact angle measurements were performed with an instrument consisting of a digital photo camera connected with a computer for digital image acquisition. 


\section{Acknowledgment}

This work was supported by the Brazilian Synchrotron Light Laboratory (LNLS) and by the Brazilian funding agencies: FAPESP, CAPES and CNPq.

\section{References}

[1] K. Mortensen, J.S. Pedersen, Structural study on the micelle formation of poly (ethylene oxide)-poly(propylene oxide)-poly(ethylene oxide) triblock copolymer in aqueous solution, Macromolecules 26 (1993) 805-812.

[2] G. Wanka, H. Hoffmann, W. Ulbricht, Phase diagrams and aggregation behavior of poly(oxyethylene)-poly(oxypropylene)-poly(oxyethylene) triblock copolymers in aqueous solutions, Macromolecules 27 (1994) 4145-4159.

[3] D. Zhao, Q. Huo, J. Feng, B.F. Chmelka, G.D. Stucky, Nonionic triblock and star diblock copolymer and oligomeric surfactant syntheses of highly ordered, hydrothermally stable, mesoporous silica structures, J. Am. Chem. Soc. 120 (1998) 6024-6036.

[4] D. Zhao, J. Feng, Q. Huo, N. Melosh, G.H. Fredrickson, B.F. Chmelka, G.D. Stucky, Triblock copolymer syntheses of mesoporous silica with periodic 50 to 300 Angstrom pores, Science 279 (1998) 548-552.

[5] M. Kruk, M. Jaroniec, C.H. Ko, R. Ryoo, Characterization of the porous structure of SBA-15, Chem. Mater. 12 (2000) 1961-1968.

[6] Y. Zhao, X. Chen, C. Yang, G. Zhang, Mesoscopic simulation on phase behavior of Pluronic P123 aqueous solution, J. Phys. Chem. B 111 (2007) 13937-13942.

[7] A.S.M. Chong, X.S. Zhao, A.T. Kustedjo, S.Z. Qiao, Functionalization of large-pore mesoporous silicas with organosilanes by direct synthesis, Microporous Mesoporous Mater. 72 (2004) 33-42.

[8] T.A. Kim, F. Kleitz, B. Paul, R. Ryoo, MCM-48-like large mesoporous silicas with tailored pore structure: facile synthesis domain in a ternary triblock copolymer-butanol-water system, J. Am. Chem. Soc. 127 (2005) 7601-7610.

[9] M.C. Chao, D.S. Wang, H.P. Lin, Controlling the crystal morphology of mesoporous silica SBA-15, Microporous Mesoporous Mater. 83 (2005) 269-276.

[10] L. Pei, K. Kurumada, M. Tanigaki, M. Hiro, K. Suza, Effect of drying on the mesoporous structure of sol-gel derived silica with PPO-PEO-PPO template block copolymer, J. Colloid Interface Sci. 284 (2005) 222-227.

[11] M.C. Chao, C.H. Chang, H.P. Lin, C.Y. Tang, C.Y. Lin, Morphological control on SBA-15 mesoporous silicas via a slow self-assembling, J. Mat. Sci. 44 (2009) 6453-6462.
[12] K. Moller, T. Bein, Inclusion chemistry in periodic mesoporous hosts, Chem. Mater. 10 (1998) 2950-2963.

[13] A. Stein, B.J. Melde, R.C. Schroden, Hybrid inorganic-organic mesoporous silicates-nanoscopic reactors coming of age, Adv. Mater. 12 (2000) 1403-1419.

[14] A. Sayari, S. Hamoudi, Periodic mesoporous silica-based organic-inorganic nanocomposite materials, Chem. Mater. 13 (2001) 3151-3168.

[15] A.S.M. Chong, X.S. Zhao, Design of large-pore mesoporous materials for immobilization of penicillin G acylase biocatalyst, Catal. Today 93-95 (2004) 293-299.

[16] M.S. Cho, H.J. Choi, K.Y. Kim, W.S. Ahn, Synthesis and characterization of polyaniline/mesoporous SBA-15 nanocomposite, Macromol. Rapid Commun. 23 (2002) 713-716.

[17] K. Ramam, M.T. Anderson, C.J. Brinker, Template-based approaches to the preparation of amorphous, nanoporous silicas, Chem. Mater. 8 (1996) 1682-1701.

[18] O. Czakkel, B. Nagy, E. Geissler, K. László, In situ SAXS investigation of structural changes in soft resorcinol-formadehyde polymer gels during $\mathrm{CO}_{2}$-drying, $\mathrm{J}$. Supercrit. Fluids 75 (2013) 112-119.

[19] A.F. Craievich, Small-angle X-ray scattering by nanostructured materials, in: S. Sakka, R. Almeida (Eds.), Handbook of Sol-gel Science and Technology, Kluwer, Norwell, 2005, pp. 161-189 v. 2.

[20] T. Freltoft, J.K. Kjems, S.K. Sinha, Power-law correlation and finite-size effects in silica particle aggregates studied by small-angle neutron scattering, Phys. Rev. B 33 (1986) 269-275.

[21] J. Teixeira, Small-angle scattering by fractal systems, J. Appl. Crystallogr. 21 (1988) $781-785$

[22] G. Leofanti, M. Padovan, G. Tozzola, B. Venturelli, Surface area and pore texture of catalysts, Catal. Today 41 (1998) 207-221.

[23] G.W. Scherer, Adsorption in aerogel network, J. Non-Cryst. Solids 225 (1998) 192-199.

[24] G.W. Scherer, S. Calas, R. Sempéré, Adsorption in sparse networks. II Silica aerogels, J. Colloid Interface Sci. 202 (1998) 411-416.

[25] G. Reichenauer, G.W. Scherer, Extracting the pore size distribution of compliant materials from nitrogen adsorption, Colloids Surf., A 187-188 (2001) 41-50.

[26] C.M. Awano, D.A. Donatti, F.S. de Vicente, D.R. Vollet, Structural characteristics of P123-modified ambient pressure drying aerogels, J. Non-Cryst. Solids 376 (2013) 182-188.

[27] A.P. Perissinotto, C.M. Awano, F.S. de Vicente, D.A. Donatti, A. Mesquita, L.F. da Silva, D.R. Vollet, Structure and diffuse-boundary in hydrophobic and sodium dodecyl sulfate-modified silica aerogels, Microporous Mesoporous Mater. 223 (2016) 196-202. 